\title{
TINJAUAN ARSITEKTUR EKOLOGIS PADA PUSAT OTOMOTIF (AUDI CENTRE, SINGAPURA)
}

\author{
${ }^{1}$ Agung Setiawan, ${ }^{2}$ Anggana Fitri Satwikasari. \\ ${ }^{1}$ Universitas Muhammadiyah Jakarta, Jakarta, Indonesia \\ 2017460074@ftumi.ac.id ${ }^{1}$, anggana.fitri@ftumi.ac.id²
}

Informasi Naskah (ft. 9 Arial)

Diterima: 10/03/2021; Disetujui terbit: 14/06/2021; Diterbitkan: 30/06/2021;

http://journal.uib.ac.id/index.php/jad

\begin{abstract}
ABSTRAK
Perkembangan dunia modifikasi pada bidang otomotif, sudah mulai banyak diminati dari berbagai lapisan, tidak hanya pria yang gemar memodifikasi, tetapi sudah mulai diminati oleh perempuan, baik tua maupun muda. Mereka saling bersaing dalam menyalurkan ide-idenya memodifikasi kendaraannya. Melhat itu kebutuhan akan pusat otomotif menjadi lebih besar, karena adanya aktifitas penggemar modifikasi yang sangat antusias. Pusat otomotif didominasi buangan gas polutan , suara bising, yang menimbulkan dampak buruk bagi lingkungan dan orang sekitar. Adanya permasalahan tersebut diperlukannya tinjauan bangunan pusat otomotif berekologis dalam perencanaannya. Arsitektur ekologis ialah ilmu yang mempelajari hubungan timbal balik antara manusia dan lingkungannya dalam merancang suatu bangunan dengan memperhatikan aspek alam sekitar. Pada penelitian ini menggunakan metode kualitatif deskriptif yang melakukan penyelidikan secara rinci dari permasalahan pada suatu objek. Setelah dilakaukan pengamatn terhadap studi kasus bangunan Audy Singapore. Pemilihan studi kasus bangunan ini terletak di singapore, mengingat negara tersebut sangat mengedepankan prinsip arsitektur berkelanjutan dan bangunan ini juga menggunakan material baru yang ramah lingkungan serta desain yang memperhatikan konsep ekologis. Dapat disimpulkan bahwa bangunan tersebut sudah hampir mendekatkan konsep arsitektur ekologis. Dengan adanya pemilihan material pada fasadnya dan mempertahankan kondisi lokal dalam perancangannya.
\end{abstract}

Kata Kunci: otomotif; pusat otomotif; arsitektur ekologis

\section{ABSTRACT}

The development of the world of modification in the automotive sector has begun to be in great demand from various layers, not only men who like to modify, but have started to be attracted by women, both young and old. They compete with each other in channeling their ideas to modify the vehicle. Seeing that the need for an automotive center is greater, due to the enthusiastic activity of modification enthusiasts. The automotive center is dominated by pollutant gas, noise, which has a negative impact on the environment and the surrounding people. The existence of these problems requires a review of the ecological automotive center building in its planning. Ecological architecture is the study of the reciprocal relationship between humans and their environment in designing a building by paying attention to aspects of the natural surroundings. In this study, using a descriptive qualitative method that conducts detailed research of the problem on an object. After doing some observations on the case study of the Audy Singapore building. The choice of this building case study is located in Singapore, considering that the country puts forward the principles of sustainable architecture and this building also uses new environmentally friendly materials and designs that pay attention to ecological concepts. It can be concluded that the building is close to the concept of ecological architecture. With the selection of materials on the facade and maintaining local conditions in the design Keyword: automotive; automotive center; ecological architecture 


\section{Pendahuluan}

Seiring perkembangan zaman, dunia modifikasi dalam bidang otomotif semakin berkembang. Hal itu karena besarnya antusias pecinta modifikasi dalam bidang otomotif, yang dimana otomotif mulai banyak diminati oleh berbagai lapisan masyarakat, baik wanita, tua maupun muda, yang dimana biasanya otomotif diminati oleh kaum pria. Peminat modifikasi bisa berupa mobil dan motor, dapat dilihat dari beberapa komunitas otomotif mobil atau motor yang memodifikasi mobil atau motornya sesuai dengan keinginannya. Peminat modifikasi sangat aktif dalam menyalurkan hobi dan ide-idenya dalam kreatifitas memodifikasi sesuai dengan harapan yang diinginkan. Hasil kreatifitas tersebut dapat disalurkan melalui kompetisi diberbagai event dan dapat dilakukan di pusat-pusat otomotif yang berkualitas. Berbicara tentang pusat otomotif di indonesia masih banyak yang perlu diperhatikan, seperti khususnya kualitas lingkungan di sekitar bangunan pusat otomotif tersebut. Pusat otomotif biasanya didominasi dengan buangan gas yang tidak baik untuk kesehatan manusia. Hal itu memberikan ketidaknyamanan pada penggunanya. Mengutip data ASEAN Automobile Federation (AAF), sejak Januari hingga Juni 2017, total produksi mobil di negara-negara ASEAN mencapai 1,97 juta. Sementara total penjualan kendaraan di semester I 2017 mencapai 1,61 juta kendaraan. Dibandingkan dengan 1,53 juta unit pada periode yang sama tahun lalu, jumlah ini meningkat sekitar $5,5 \%$. Hal ini membuat kebutuhan akan pusat otomotif semakin meningkat,akan tetapi pembangunan pusat otomotif sumber terjadinya perusak ekosistem karena bahayanya limbah buangan polutan. Melihat permasalahan tersebut ada hal yang perlu diperhatikan dalam pengembangan Pusat Otomotif yang ekologis agar tidak terjadinya pencemaran lingkungan dan kekhawatiran masyarakat akan kesehatan.

Arsitektur ekologi adalah studi tentang keterkaitan antara makhluk hidup dan lingkungannya. Menurut Ching, Francis D.K., (2007) Ekologi berasal dari bahasa Yunani "oikos" dan "logos", oikos berarti rumah tangga atau cara bertempat tinggal, dan logos berarti ilmu atau bersifat ilmiah. Arsitektur ekologi juga merupakan ilmu yang mengajarkan bagaimana desain harus memperhatikan hubungan sosial budaya. Arsitektur tidak bisa lepas dari tindakan perusakan lingkungan. Prinsip utama arsitektur ekologis adalah menghasilkan keselarasan antara manusia dengan lingkungan alamnya. Hal ini menunjukan bahwa arsitektur adalah ekologis ilmu yang bersifat kompleks dalam memperhatikan kondisi lingkungan alamnya. dari penjelasan di atas konsep arsitektur ekologis dapat menjadi salah satu solusi untuk mencegah pencemaran lingkungan pada bangunan pusat otomotif. pada penelitian ini akan dilakukan tinjauan terhadap prinsip konsep arsitektur ekologis agar dapat memahami langkah-langkah yang perlu dipertimbangkan untuk menjaga kualitas lingkungan alam di bangunan pusat otomotif. 


\section{Kajian Pustaka}

\subsection{Pengertian Otomotif}

Menurut penelitian Putra (2019) otomotif merupakan ilmu yang mempelajari kendaraan transportasi darat dengan menggunakan mesin khususnya mobil dan sepeda motor. Dalam waktu setahun, jumlah kendaraan bermotor di Indonesia mengalami peningkatan setiap tahunnya. Meningkatnya jumlah kendaraan bermotor ini menandakan bahwa perekonomian dan kebutuhan akan kendaraan semakin tinggi, hal itu dapat dilihat dari tingkat kendaraan bermotor yang sangat pesat. Maka dari itu, otomotif dapat mempengaruhi ekonomi industri dan perdaganan yang berpotensi sangat besar pada suatu negara.

\subsection{Pengertian Pusat Otomotif}

Menurut Muhammad Najib, dkk (2013) pusat otomotif adalah suatu wadah penjualan kendaraan bermotor yang dibangun dengan tata letak tampilan yang menarik, sehingga semakin diminati masyarakat. Sebagai bangunan yang dapat menjadi ciri produk Pusat otomotif ialah suatu tempat yang memberikan fasilitas untuk penggemar modifikasi dalam bidang otomotif untuk menciptakan ide-ide dalam memodifikasi kendaraannya menjadi lebih indah dan elegan dari standar kendaraan pada umumnya. Sedangkan Menurut Cahyono (2006) pusat otomotif merupakan suatu wadah penjualan dan pembelian, juga sebagai sarana untuk mempromosikan barang produksi khusus otomotif dan barang-barang penunjang lainnya yang dikemas dalam suatu wadah / tempat yang modern dengan segala fasilitas yang mendukung kegiatan tersebut didalamnya.

\subsection{Pengertian Arsitektur Ekologis}

Menurut Syaid , Ashadi, \& Luqmanul (2018) Konsep ekologi mengacu pada konsep pengelolaan lingkungan melalui pemanfaatan potensi atau sumber daya alam dan pemanfaatan teknologi berbasis pengelolaan etis yang ramah lingkungan. Selain itu, arsitektur ekologis adalah studi arsitektur yang berawasan lingkungan alam. Arsitektur ekologis pada umumnya memperhatikan kualitas hidup bagi penggunanya, dengan memperhatikan beberapa aspek yang tidak merusak lingkungan, dimana memanfaatkan potensi alam semaksimal mungkin. Sedangkan menurut Frick (1998) arsitektur ekologis merupakan ilmu yang mempelajari antara kebutuhan tempat tinggal untuk kehidupan manusia dengan lingkungan alamnya, yang didalamnya mengandung beberapa bagian dengan bagian yang memperhatikan kesehatan manusia. Arsitektur Ekolgois juga ilmu yang mengajarkan bagaimana dalam merancang harus memperhatikan hubungan sosial-kultural. Hal ini menunjukan bahwa arsitektur ekologis ilmu yang bersifat kompleks dalam memperhatikan kondisi lingkungan alamnya.

\subsection{Prinsip-Prinsip Arsitektur Ekologis}

Menurut Ryn \& Cowan (1996 ) mengemukakan prinsip-prinsip desain yang ekologis, antara lain:

\section{Solution Grows from Place (Solusi Tumbuh dari Tempat)}

Prinsip menjelaskan atas berbagai permasalahan yang ada pada lingkungan. Dengan memanfaatkan potensi dan sumber daya lingkungan untuk mengatasi setiap persoalan desainnya. Prinsip ini menekankan pentingnya pemahaman terhadap adalam dan masyarakat lokal, dengan memahami hal tersebut maka 
dapat mendesain lingkungan binaan tanpa menimbulkan kerusakan alam maupun kerusakan dari manusianya itu sendiri.

2. Ecological Accounting Informs Design (Penghitungan Ekologis Menginformasikan Desain)

Prinsip ini menjelaskan tentang perhitungan-perhitungan ekologis untuk memperkecil dampak negatif terhadap lingkungan. Keputusan desain yang digunakan harus sekecil mungkin memberikan dampak negatif terhadap lingkungan.

3. Design with Nature ( Desain dengan Alam )

Arsitektur merupakan bagian dari alam, maka dari itu desain arsitektur harus mampu menjaga kelangsungan hidup setiap unsur ekosistem yang ada didalamnya, sehingga tidak merusak lingkungan. Prinsip ini menekankan pada pemahaman mengenai proses hidup (living process) di lingkungan yang akan diubah atau dibangun.

4. Everyone is a Designer (Setiap orang adalah Desainer )

Melibatkan setiap pihak Melibatkan setiap pihak yang terlibat dalam proses desain. Tidak ada yang bertindak sebagai user atau participant saja atau designer / arsitek saja. Setiap orang adalah participant-designer. Setiap pengetahuan yang dimiliki oleh siapapun dan sekecil apapun harus dihargai. Jika semua orang bekerjasama untuk memperbaiki lingkungannya, maka sebenarnya mereka memperbaiki diri mereka sendiri

5. Make Nature Visible (Jadikan Alam Terlihat )

Prinsip ini menjelaskan proses-proses alamiah merupakan proses yang siklis. Arsitektur sebaiknya juga mampu untuk melakukan proses tersebut sehingga limbat yang dihasilkan dapat ditekan seminimal mungkin.

\subsection{Unsur-Unsur Pokok Arsitektur Ekologis}

Menurut Frick (1998). Pada bukunya, unsur-unsur pokok Arsitektur Ekologis mempunyai tiga Unsur, yaitu : Udara (angin), air, tanah (bumi), dan api (energi). Ketiga unsur tersebut merupakan awal hubungan tumbal balik antara bangunan gedung dan lingkungan. Arsitektur ekologis memperhatikan siklus yang terjadi di alam dengan udara, air, tanah, dan energi sebagai unsur utama yang perlu untuk diperhatikan.

1. Udara merupakan campuran berbagai gas seperti (nitrogen, oksigen, hidrogen, dll.) yang dihirup oleh manusia ketika bernapas Udara memiliki hubungan yang erat dengan kehidupan manusia. Apabila kualitas udara tercemar maka akan mengganggu sistem pernafasan dan kualitas hidup manusia.

2. Air merupakan elemen yang mendukung keberlangsungan hidup manusia. Air digunakan untuk menunjang kegiatan dan aktivitas sehari-hari yang dilakukan oleh manusia, seperti minum, mandi, mencuci, dan lain-lain. Tapi air juga menjadi sesuatu yang penting untuk kelangsungan hidup organisme lain (seperti tumbuhan dan hewan) yang ada di alam.

3. Tanah (bumi) merupakan asal dari seluruh sumber bahan baku yang menunjang keberlangsungan hidup dari seluruh makhluk hidup.

4. Energi merupakan elemen yang melambangkan kekuatan yang diperlukan

47 | 」ח-Vol.02/No.01, Juni 2021 
manusia dalam melaksankan aktivitasnya. Setiap aktivitas yang dilakukan manusia membutuhkan energi, sama seperti manusia membutuhkan energi untuk menghasilkan makanan dan peralatan.

\section{Metode Penelitian}

Pada penelitian kali ini menggunakan metode penelitian deskriptif kualitatif. Menurut Anugrah (2019) Penelitian deskriptif kualitatif merupakan metode penelitian yang menggunakan data kualitatif dan menggambarkan sejarah. Jenis penelitian deskriptif kualitatif ini biasanya digunakan untuk menganalisis peristiwa, fenomena atau situasi sosial. Arsitektur ekologi juga mencakup dimensi waktu, Alam, sosial budaya, ruang dan teknologi bangunan. Struktur ekologisnya sangat rumit, berisi bagian dari arsitektur biologis (Manusia dan Kesehatan) dan Biologi. Oleh karena itu, arsitektur ekologis bersifat holistik dan mencakup semua situs. Pada tahapan hasil dan pembahasan akan melakukan tinjauan arsitektur ekologis pada bangunan pusat otomotif Audy Centre Singapure yang akan dijelaskan secara spesifik dengan melihat lima (5) prinsip arsitektur ekologis.

\section{Hasil dan Pembahasan \\ Audi Centre, Singapura}

Bangunan Audi Centre adalah showroom Audi terbesar di Asia Tenggara. Bangunan ini memiliki desain modern yang melambangkan Audi sebagai perusahaan terbesar di dunia. Audi Centre berlokasi di 281 Alexandra Rd Singapura 159938 dengan luas 1.350 meter persegi per lantai. Audi Centre merupakan bangunan yang memfasilitasi kebutuhan akan kendaraan beroda empat yang memiliki karakteristik sesuai dengan fungsinya. Konsep desain bangunan dibuat untuk melokalkan tempat Audi Terminal internasional agar sesuai dengan situs dan kondisi lokal, selain itu juga menyimbolkan sebagai perusahaan yang konsisten.

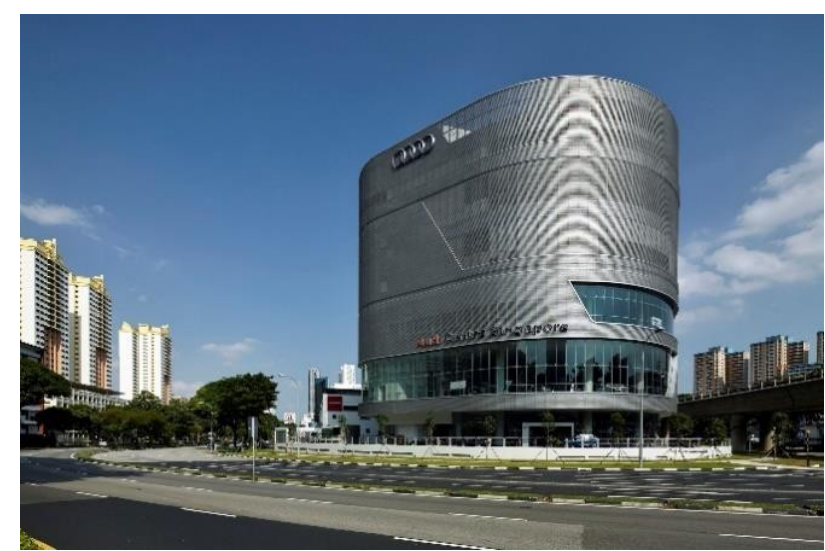

Gambar 1. Kondisi Eksisting Bangunan

Audi Centre Sumber:

Archdaily, 2020

\section{Analisis Studi Kasus Bangunan Audy Singapura}

\section{a. Solution Grows from Place (Solusi Tumbuh dari Tempat)}


Konsep desain bangunan terbentuk untuk melokalkan template Audi Terminal internasional agar sesuai dengan situs dan kondisi lokal, dan memastikan merek perusahaan yang konsisten. Oleh karena itu, meskipun bangunan berbentuk setengah lingkaran tidak seperti umumnya dan terwujudnya orientasi bangunan, karena dapat menyesuaikan tapak, sehingga dampaknya tidak merusak lingkungan sekitarnya, dan menampilakan khas Audi terlihat jelas pada desain bangunan.

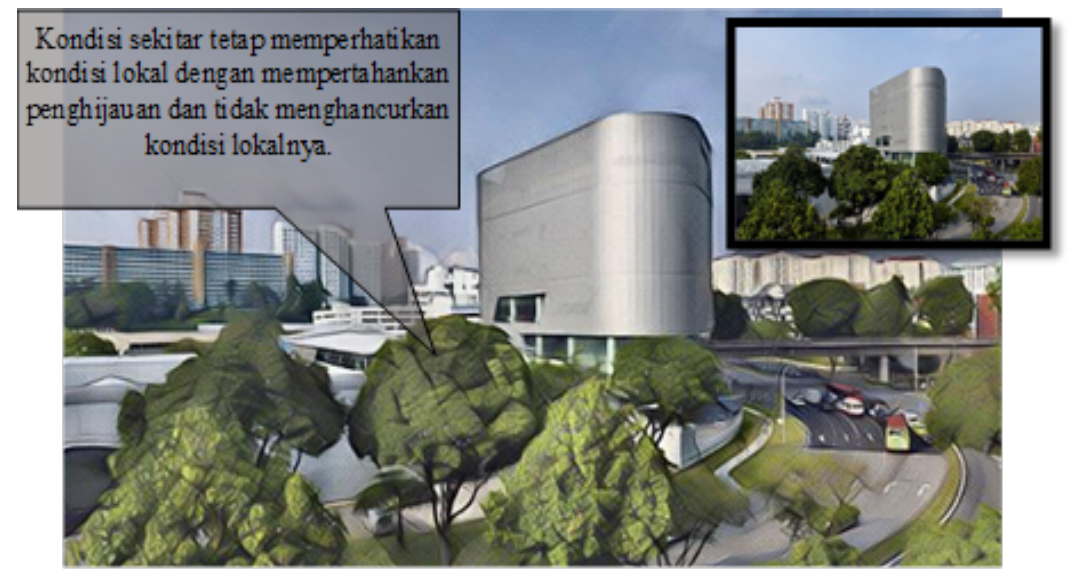

Gambar 2. Analisis Penerapan Solution Grows from Place

Sumber : Analisis Pribadi, 2020

\section{b. Ecological Accounting Informs Design (Penghitungan Ekologis \\ Menginformasikan Desain)}

Konsep desain arsitektural dengan fragmen heksagonal (hexagonal) membentuk pola sarang lebah, dan jendela kaca setinggi penuh di lantai bawah membuat bangunan tampak melayang dari tanah, sehingga menyesuaikan kontur tanah dan antara fondasi dan tanah jarak. Pilar jalur MRT. Konsep desain dibentuk oleh kondisi lokal di persimpangan berbentuk T. Jalan Leng Kee dan Jalan Alexandra. Terminal penumpang Audi juga harus bersaing ketat dengan jalur kereta MRT dalam desain untuk menghindari efek buruk pada bangunan atau kerusakan pada Jalur MRT.

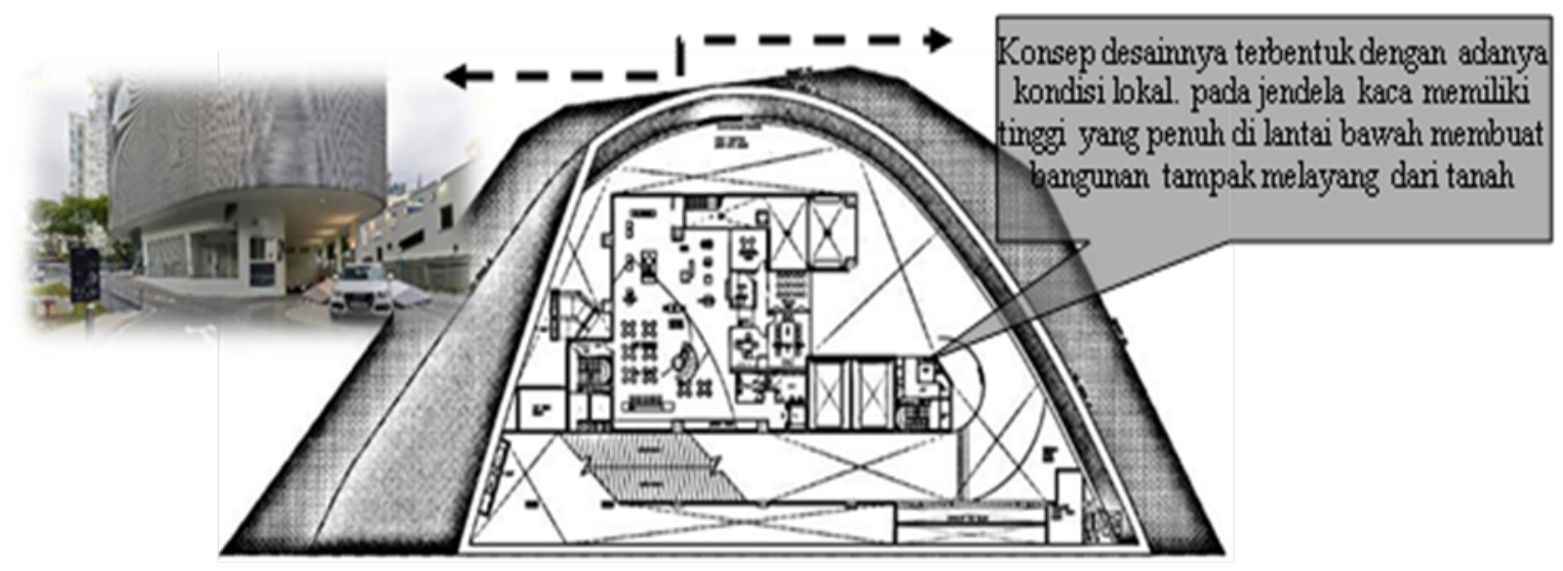


Gambar 3. Ecological Acounting Informs Design

Sumber : (Analisis pribadi, 2020 )

\section{c. Design with Nature (Desain dengan Alam )}

Desain bangunan melengkung dan kaca sebagai bentuk sistem pasif, fasad bangunan dilapisi aluminium, sehingga interior bangunan dapat memperoleh cahaya alami. Dengan cara ini, dapat meminimalkan penggunaan pencahayaan buatan pada siang hari dan membuat gedung Audi Center Singapura hemat energi dan berkelanjutan.

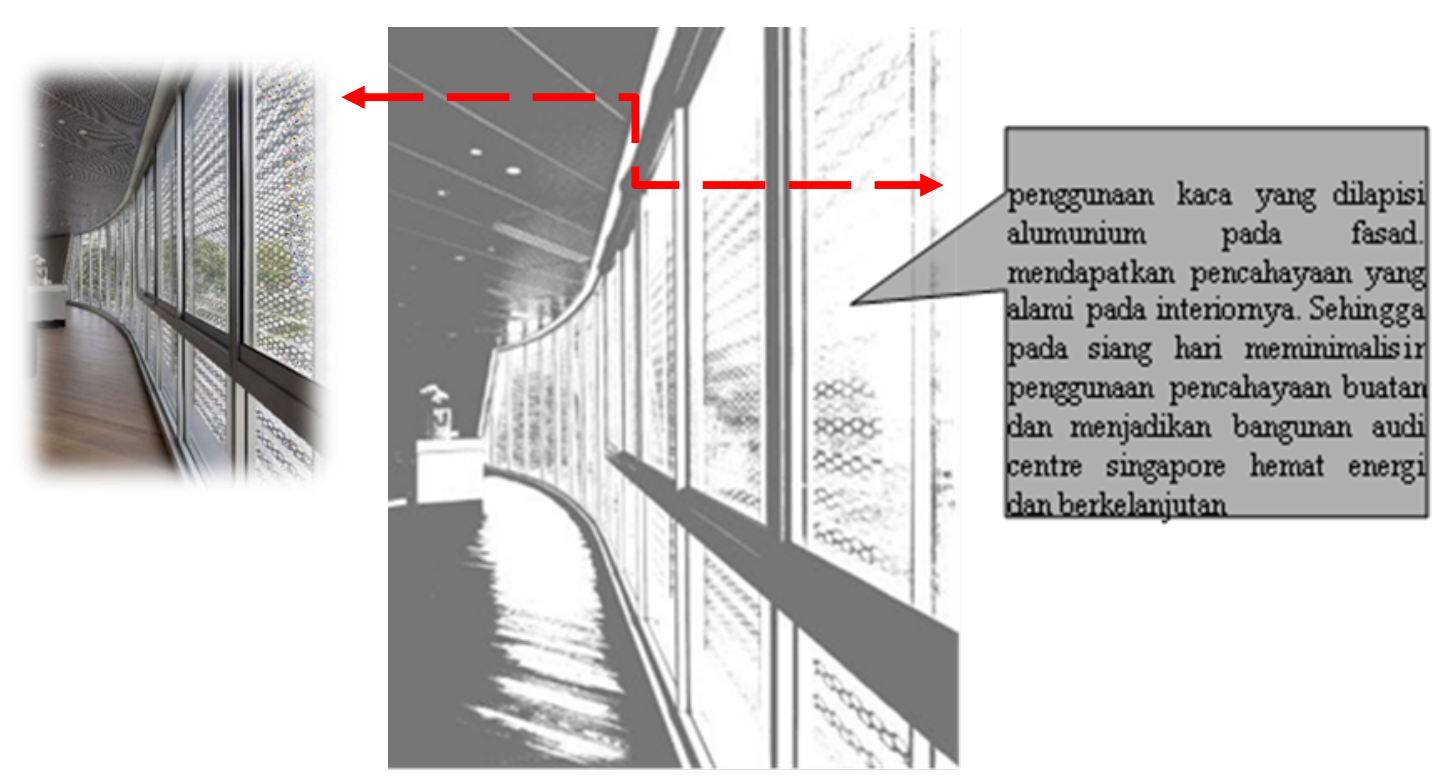

Gambar 4. Design with Nature

Sumber : Analisis Pribadi, 2020

\section{d. Everyone is a Designer (Setiap orang adalah Desainer )}

Desain Terminal Audi adalah prestasi kreativitas yang tetap setia dan konsisten pada merek Audi. Tahap perancangannya desainnya mengikuti prestasi merek Audi yang hanya melibatkan owner dan Architec, sehingga menghasilkan bentuk bangunan setengah lingkaran dan elemen-elemen dinding yang melengkung. Meskipun begitu bangunan ini berhasil mengukuhkan tempatnya sebagai landmark di lanskap lokal singapore. 


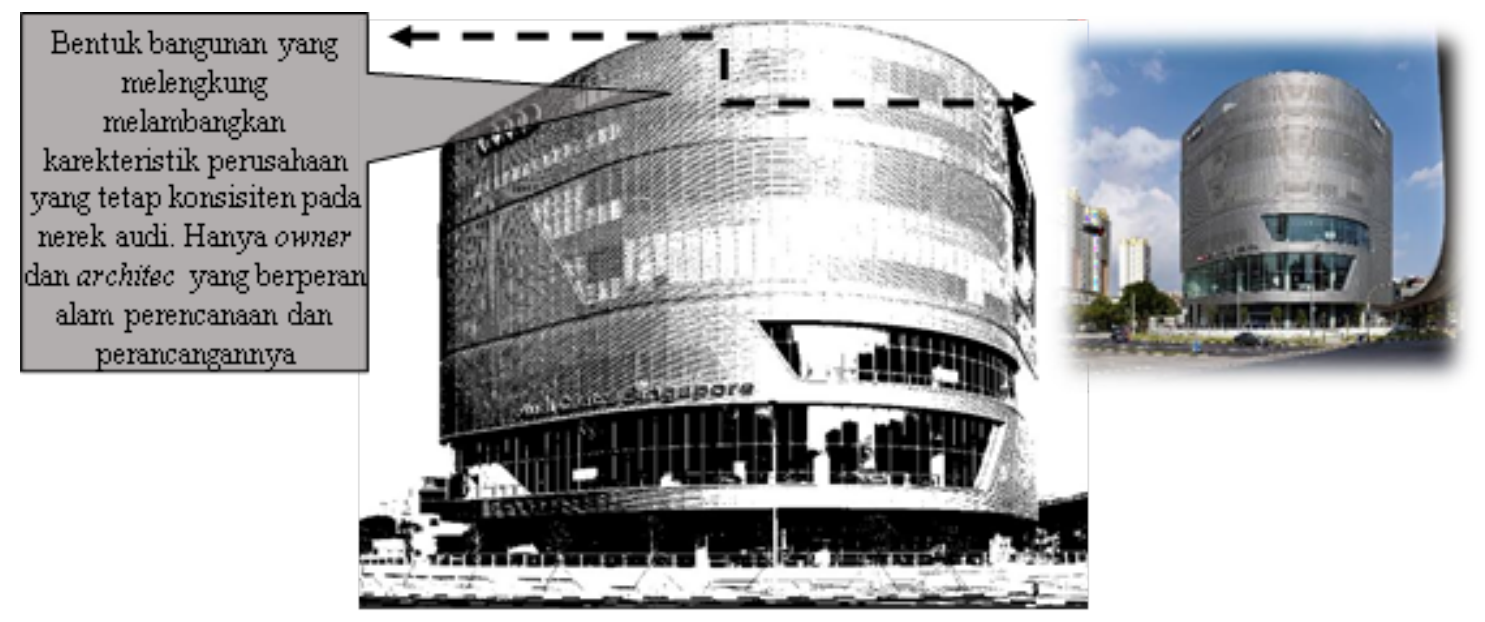

Gambar 5. Everyone is a Designer 2.

Sumber : Analisis Pribadi, 2020

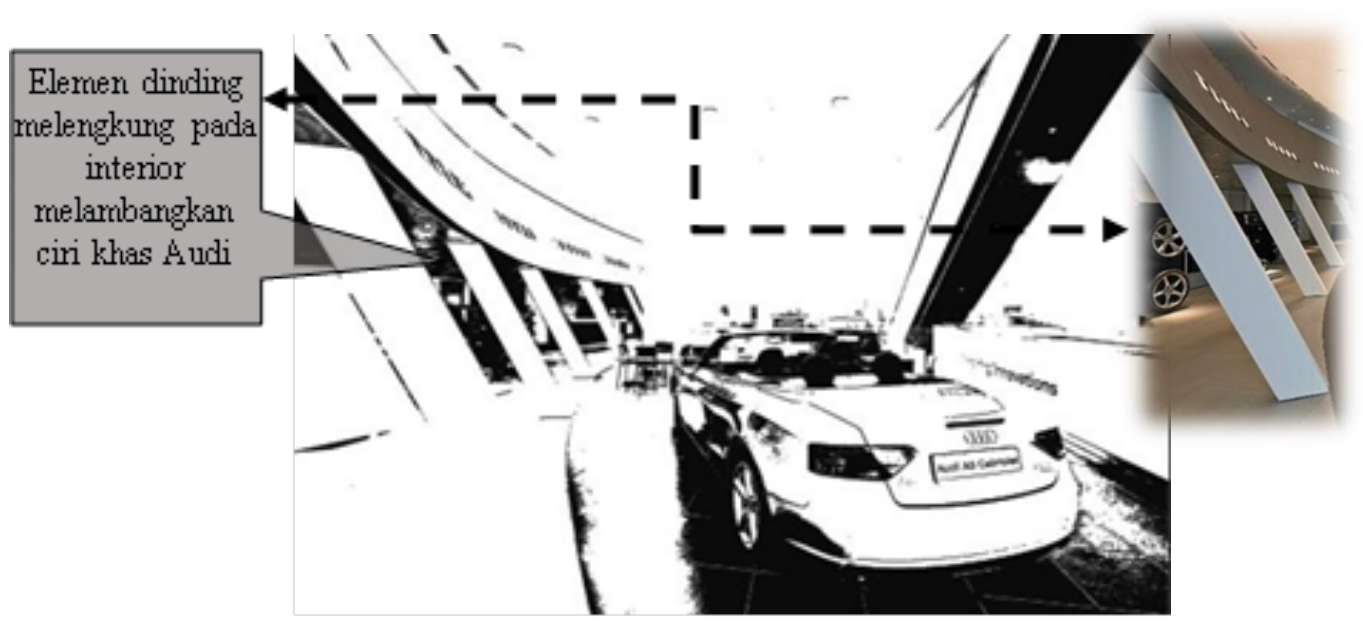

Gambar 6. Interior Bangunan Audi centre Singapore Sumber : Analisis Pribadi, 2020

\section{e. Make Nature Visible ( Jadikan Alam terlihat )}

Bangunan audi centre singapore memperhatikan kondisi alam sekitar yang menjadikan bahwa adanya alam terlihat sebagi bentuk perancangan bangunan yang menunjukan aspek keberlangsungan hidup agar tidak terdampak buruk untuk lingkungan sekitar. Fasad bangunan Audi centre singapore dilapisi aluminium, sementara pada jendela kaca memiliki tinggi yang penuh di lantai bawah membuat bangunan tampak melayang dari tanah. Namun dalam penerapan dari segi limbahnya, bangunan ini masih minim diaplikasikan. 


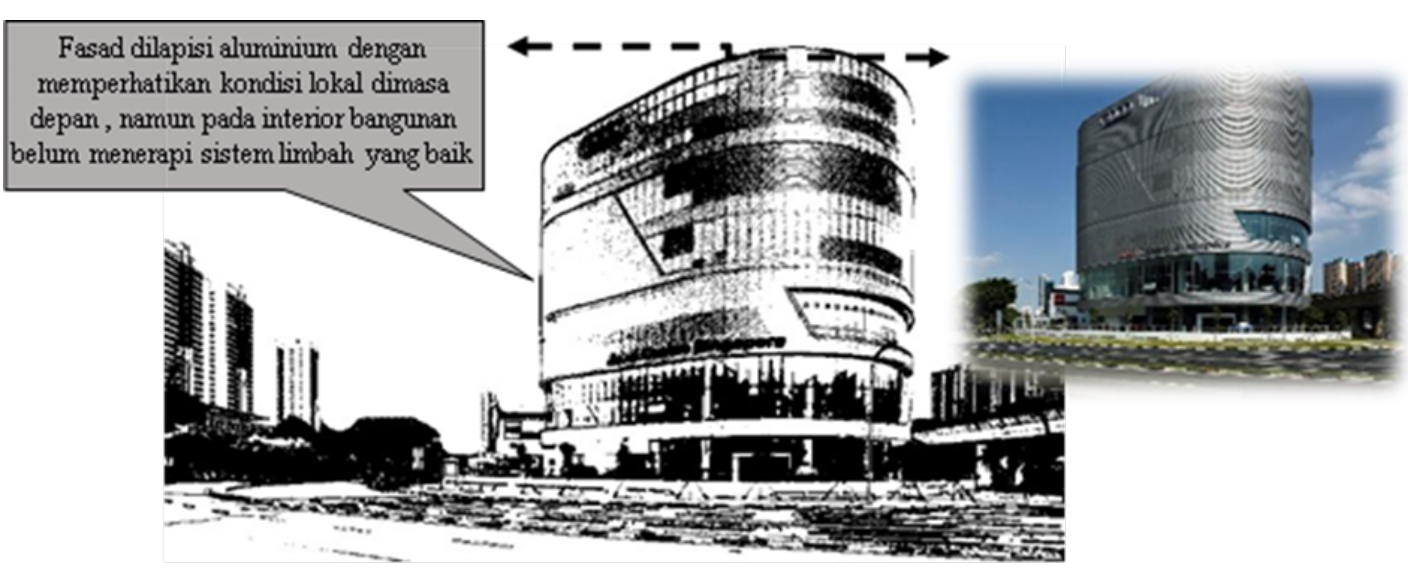

Gambar 4. 1 Make Nature Visible 2.

Sumber : Analisis pribadi, 2020

\section{Kesimpulan}

Kesimpulan didapat setelah melakukan pembahasan yang dianalisis dengan pertimbangan pada lima (5) Prinsip Arsitektur Ekologis. bahwa bangunan Audy Singapura berdiri setinggi delapan lantai, toko andalan Audi Singapura yang baru diresmikan adalah Audy terminal bertingkat tinggi pertama, dan dengan luas 1.350 meter persegi per lantai, juga merupakan showroom Audi terbesar di Asia Tenggara. Konsep desainnya adalah untuk melokalkan template Audi Terminal internasional agar sesuai dengan situs dan kondisi lokal lingkungan sekitar. Selain itu memastikan merek perusahaan yang konsisten pada desain bangunan. Oleh karena itu, meskipun kendala ruang mengakibatkan bangunan berbentuk setengah lingkaran tidak seperti biasanya, tampilan khas Audi terlihat jelas dalam elemen- elemen seperti dinding lengkung bangunan. Fasadnya dilapisi aluminium dengan potongan heksagonal membentuk pola sarang lebah, yang meminimalisir pencahayaan buatan pada suang hari. sementara jendela kaca setinggi penuh untuk lantai bawah membuat bangunan tampak melayang dari tanah.

Desain Terminal Audi adalah prestasi kreativitas yang tetap setia pada merek Audi sekaligus berhasil mengukuhkan tempatnya sebagai landmark di lanskap lokal. Hal ini menunjukan bahwa dalam penerapan konsep Arsitektur Ekologis di bangunan Audi Singapore sudah hampir mendekati sesuai dengan prinsip-prinsip arsitektur ekokogis. Hanya saja dalam perancangannya masih belum terlihat pertimbangan akan limbah buangan yang dihasilkan bangunan tersebut dalam hal pengendaliannya. Selain itu dalam terwujudnya bentuk desain melibatkan beberapa lapisan. Seperti, owner, perancang, dan masyarakat lokal. Sehinga menjadikan bangunan tersebut sebagai sebuah ikon yang mempunyai karakteristik perusahaan audy dan menjadikan sebuah bangunan unik di kota Singapore. 


\section{DAFTAR PUSTAKA}

Anugrah , s. a. (2019, 08 08). https://hot.liputan6.com/read/4032771/mengenal-jenispenelitian-deskriptif-kualitatif-pada-sebuah-tulisan ilmiah\#: :text=Jenis\%20penelitian\%20deskriptif\%20kualitatif\%20merupakan,feno mena\%2C\%20atau\%20keadaan\%20secara\%20sosial. Retrieved from liputan6.

Ching, Francis D.K. (2007). Arsitektur Teori (ketiga ed.). Jakarta: Erlangga.

Cahyono, A. B. (2016). Pusat Otomotif diSemarang. 2.

Frick, H. (1998). dasar-dasar eko-arsitektur (1 ed.). yogyakarta: kanisius.

Frick, H. (2006). Arsitektur Ekologis (2 ed.). yogyakarta: kanisius.

Muhammad Najib, dkk. (2013). Pusat Otomotif Honda Tunjungann,2.

Ryn , S. V., \& Cowan, S. (1995, 11 3). Desain Ekologi Desain. United States of America: Island Press. From Desain Ekologis: http://dev.ecoguineafoundation.com/uploads/5/4/1/5/5415260/ecological_design_ 10th_edition.pdf

Ryn, V. S., \& Cowan, S. (1996 ). Ecological Design. United States of America: Island Press.

From http://dev.ecoguineafoundation.com/uploads/5/4/1/5/5415260/ecological_design_ 10th_edition.pdf

Syaid , a., ashadi, \& luqmanul, h. (2018). jurnal arsitektur purwarupa. PENERAPAN KONSEP ARSITEKTUR EKOLOGI PADA PERANCANGAN KAWASAN. 